\title{
EXPERIMENTO: A PARIDADE NO LANÇAMENTO DE 2 DADOS
}

\author{
Pedro Augusto Soares da Silva ${ }^{1}$, Maria Luiza Carvalho de Sousa Ribeiro², Nallyson \\ Francisco Silva Sousa ${ }^{3}$, , MsC. Francismar Holanda ${ }^{4}$ \\ 1 - Graduando IFPI, pedroaugusto.thay00@gmail.com, \\ 2 - Graduando IFPI, luizamjp@ hotmail.com \\ 3 - Graduando IFPI, nallyson@ hotmail.com \\ 4 - Professor IFPI, frholanda@ifpi.edu.br
}

\section{INTRODUÇÃO}

Os dados são talvez a forma mais antiga de se "tirar a sorte". Sua origem é antiquíssima, confundindo-se com a origem das artes divinatórias. Objetos mágicos e lúdicos, obviamente, os primeiros "dados" pouco se pareciam com os dados atuais. Normalmente eram dados binários, isto é, de dois lados, que davam, obviamente, somente um de dois resultados possíveis, como uma moeda no jogo de "cara ou coroa". Eram utilizadas conchas, chifres, dentes, marfim, argila, porcelana, cristal, mármore enfim, qualquer material e meio que pudesse diferenciar um lado de outro.

A discussão sobre a importância dos jogos no ensino aprendizagem de Matemática vem se concretizando, pois os alunos no geral possuem uma grande potencialidade de refletir e aplicar de maneira prática sua capacidade de determinar várias situaçõesproblemas, caracterizando objetos e buscando uma linha de resolução baseada em esclarecimentos próprios. A proposta de um jogo em sala de aula é muito importante para o desenvolvimento social, pois existem alunos que por timidez se "fecham", e evitam perguntar sobre determinados conteúdos, de expressar dúvidas, e com isso aprender Matemática se torna um problema para eles.

A maior parte desses problemas encontrados no ensino de Matemática se deve, entre muitos fatores, a falta de contextualização e do caráter experimental das aulas e dos conteúdos ministrados. Conforme afirma Piaget (1977), o conhecimento "realiza-se através de construções contínuas e renovadas a partir da interação com o real", portanto um ensino baseado apenas em aulas expositivas no quadro e resolução de exercícios não proporciona a construção do conhecimento por parte dos próprios alunos.

Esse experimento tem como principal objetivo relacionar conteúdos matemáticos ao lançamento de dados, estabelecendo os resultados de cada lançamento para que logo após se defina o valor de soma e produto de ambos a fim de definir o percentual de cada operação realizada e por fim a comparação de cada um especificando de maneira quantitativa e qualitativa os mesmos. 


\section{FUNDAMENTAÇÃO TEÓRICA}

No campo da matemática a paridade, isto é, a qualidade de ser par ou ímpar, da soma e produto de dois números só depende da paridade de cada um dos números e não dos números em si, em outras palavras se trata da definição de um valor lógico para um determinado resultado específico dependendo da operação utilizada.

A probabilidade é o estudo de experimentos que, mesmo realizados em condições bastante parecidas, apresentam finalidades impossíveis de prever. Como por exemplo o lançamento de uma moeda que, mesmo realizado repetidas vezes, não pode ser previsto, pois, cada vez que a moeda for lançada, o resultado pode ser diferente, ou mesmo no lançamento de dois dados que assim como a moeda também não é possível prever os resultados, nesse caso a aplicação da mesma se dá por suposições dos possíveis ou mais prováveis valores.

A probabilidade associa números às chances de determinado resultado acontecer, de modo que, quanto maior esse número, maior a chance desse resultado ocorrer. Existe um mínimo resultado onde representa a impossibilidade de ocorrer assim como, um maior número, que representa a certeza de determinado resultado. No lançamento de um dois dados, por exemplo, é impossível ocorrer a soma de números igual a 13 e existe a certeza de ocorrer um número menor que 13 ou maior que 0.

\section{METODOLOGIA}

Esta pesquisa tem como metodologia um estudo de caso, na forma de experimento onde foram necessários dois dados, que foram lançados 100 vezes simultaneamente, e os resultados foram anotados e tabulados para análise.

Foram feitos os seguintes procedimentos:

-Lançamento dos dados simultaneamente;

-Anotação dos resultados

-Tabular os resultados de soma e produto;

-Os resultados foram anotados;

-O processo dos itens acima foi repetido para os 99 lançamentos de dados restantes; 


\section{Congresso Internacional das Licenciaturas COINTER - PDVL 2017}

-Após o termino dos lançamentos e do procedimento de soma e produto, os resultados de cada categoria foram apurados e separados como sendo pares ou impares;

Lançamentos devidamente anotados e apurados.

\begin{tabular}{|c|c|c|c|c|c|c|c|c|c|c|c|c|}
\hline$\pi$ & & & thow & mentef & + & & $x$ & & & hower & mado & -1 \\
\hline 15 & $I$ & 28 & 6 & 6 & 42 & $P$ & 36 & $\beta$ & 55 & 3 & 5 & 86 \\
\hline As & $I$ & 29 & 6 & $S$ & 11 & s & 30 & $P$ & 56 & 3 & 4 & 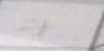 \\
\hline 2 & $P$ & 30 & 2 & 5 & 7 & 3 & 10 & $P$ & 57 & 4 & 6 & 10 \\
\hline 30 & $P$ & 31 & 2 & 2 & 4 & $P$ & 4 & $P$ & 58 & 1 & 3 & 4 \\
\hline 12 & $P$ & 32 & 6 & 5 & 11 & 3 & 30 & P & 59 & 1 & 3 & 45 \\
\hline 8 & $P$ & 33 & 3 & 2 & 5 & 3 & 6 & $P$ & 60 & 6 & 1 & + \\
\hline 16 & $P$ & 34 & 1 & 1 & 2 & $P$ & 1 & 3 & 61 & 3 & 3 & 6 \\
\hline 2 & $P$ & 35 & 2 & 2 & 4 & $P$ & 4 & $P$ & 62 & 4 & 6 & NO \\
\hline & $P$ & 36 & 3 & 2 & 3 & 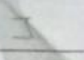 & 6 & $P$ & 63 & 4 & 2 & \\
\hline 4 & $P$ & 37 & 2 & 5 & 7 & & & $P$ & 64 & 6 & 3 & 마 \\
\hline & $\rho$ & 38 & $\sum_{1}$ & 3 & 7 & 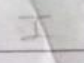 & 1 & $\nabla$ & 65 & 4 & 4 & \\
\hline & $I$ & 39 & 1 & 4 & 5 & - & & & 8 & & 4 & \\
\hline & $P$ & 40 & 4 & 1 & 5 & - & 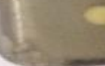 & & 9 & $\beta$ & 6 & \\
\hline & $P$ & 41 & 3 & 3 & 6 & $P$ & 8 & 3 & 68 & 5 & 3 & \\
\hline & I & 42 & 1 & 5 & 6 & $P$ & & 8 & 69 & 1 & 6 & \\
\hline & & 43 & 4 & 4 & 5 & - Is & 4 & $P$ & 70 & A & 2 & \\
\hline
\end{tabular}




\section{Congresso Internacional das \\ Licenciaturas \\ COINTER - PDVL 2017}

\section{RESULTADOS}

De acordo com os resultados obtidos percebemos que nessa sequência de lançamentos feitos os resultados distribuídos entre pares e impares tiveram uma porcentagem diferente do que se esperava tendo como base a teoria de chances iguais para números pares e impares. Isso aconteceu devido ao fato de que na teoria estamos lidando com probabilidades, ou seja, com as chances que algo tem para ocorrer em determinada situação. Portanto, visto que as chances não são de $100 \%$ para cada categoria analisada, não há uma garantia de que os resultados teóricos possam se concretizar durante a execução de uma situação.

\begin{tabular}{|c|c|}
\hline SOMA & PRODUTO \\
\hline PARES: $45 \%$ & PARES: $71 \%$ \\
\hline ÍMPARES: $55 \%$ & ÍMPARES: $29 \%$ \\
\hline
\end{tabular}

\section{CONCLUSÂO}

Se espera que ao fim desse experimento, o aluno seja capaz de perceber a importância dos jogos matemáticos para o seu conhecimento e ampliar o mesmo para repassar a outros além de poder se divertir e entreter coletando diferentes resultados percentuais que esse experimento possa a ter, enfim se torna bastante gratificante o aprendizado por despertar a curiosidade de muitos.

As aulas de Matemática com caráter experimental, possibilitam aos alunos uma visão concretizada dos conceitos trabalhados através de aulas expositivas tradicionais. Por meio desses experimentos os alunos poderão ver a Matemática como ela é, ativa em cada aspecto da vida, o que pode levar a uma melhora no rendimento escolar dos mesmos. Esses e outros motivos por sua vez preparam os discentes para atuar na sociedade e transformá-la em algo melhor.

Portanto, cabe ao professor de Matemática ,com o apoio da escola, planejar e aplicar os experimentos práticos ao seu capital de metodologias de ensino. Somente com a teoria aliada à prática o docente na área da Matemática poderá cumprir seu papel de ressignificar os conhecimentos matemáticos e torna-los acessíveis à sociedade. Uma vez 
que isso for amplamente aplicado ao longo das aulas, o professor de Matemática irá beneficiar várias gerações com uma formação de qualidade que não ficará apenas para o período de avaliação, mas sim um conhecimento matemático significativo que perpetuará durante toda a vida de cada aluno formado.

\section{REFERÊNCIAS}

HEFEZ, A. Elementos de Aritmética. [S.l.: s.n., s.d.] (Série Textos Universitários, Sociedade Brasileira de Matemática.)

HEFEZ, A. Indução Matemática. http://www.obmep.org.br

B. R. James. Probabilidade: Um Curso em Nível Intermediário. IMPA, Rio de Janeiro, 3 edn., 2004

SILVA, Luiz Paulo Moreira. "O que é probabilidade?"; Brasil Escola. Disponível em 〈http://brasilescola.uol.com.br/o-que-e/matematica/o-que-e-probabilidade.htm>.

PIAGET, Jean. O desenvolvimento do pensamento: equilibração das estruturas cognitivas. Dom Quixote, Lisboa, 1977. 